www.jmscr.igmpublication.org

Index Copernicus Value: 79.54

ISSN (e)-2347-176x ISSN (p) 2455-0450

crossrefDOI: https://dx.doi.org/10.18535/jmscr/v7i2.61

\title{
Prevalence of "unexpected antibodies" in patients requiring blood transfusion at National Referral Hospital, Thimphu from 2015 to 2017: Retrospective study
}

\author{
Authors \\ Mahrukh Getshen ${ }^{1}$, Tshering Yangdon*², Lobzang Tashi ${ }^{3}$, Dorji Wangchuk ${ }^{4}$ \\ ${ }^{1-4}$ National Blood Bank, Department of Pathology and Laboratory Medicine, JDWNRH, Thimphu \\ *Corresponding Author \\ Tshering Yangdon \\ Email: yangdontshering2013@gmail.com
}

\begin{abstract}
Safe blood transfusion involves pre-transfusion compatibility testing including $A B O$ and Rh typing, cross match testing and screening for unexpected antibodies. Unexpected antibodies are those other than naturally occurring (Hyung Joon Kim, 2013) anti-A and anti-B antibodies which can cause transfusion reactions such as acute or delayed hemolytic transfusion reaction. The aim of the study was to investigate the prevalence of unexpected antibodies in patient samples received by Blood Bank. A total of 39,655 antibody screening was performed from 2015-2017 using standard tube method with commercially available screen cells. The overall prevalence of alloantibodies were $0.39 \%$ with higher rate in females 76.5\% than males (23.5\%). Anti-Lea was the most commonly encountered alloantibodies (56.05\%). Antibodies belonging to Rh system accounted for $11.47 \%$ and remaining $24.2 \%$ were undetected. Patients with unexpected alloantibodies may cause delayed transfusion reaction. Considering the delay in antibody testing and identification, it is vital to perform antibody screening for the donor units, so that the compatible blood unit will be accessible at times of need.
\end{abstract}

\section{Introduction}

Blood Bank caters to the patient anemic management during surgeries as well as during pre-operative care. Blood Bank performs the blood compatibility testing prior to blood transfusion. The American Association of Blood Bank (AABB) has recommended that $\mathrm{ABO}$ typing, Rh typing, unexpected antibody screening, and crossmatching must be performed before a blood transfusion (Hyung Joon Kim, 2013).

Unexpected antibodies, also called irregular antibodies, are antibodies whose existence in a person's serum cannot be known before testing is performed, and they include alloantibodies against such antigens as Rh, MNSs, Duffy, and Kidd (Han KS, 2006) (Ki-Ho Ko, 2012) Unexpected antibodies are very important clinically because they may cause critical transfusion reactions such as acute or delayed hemolytic transfusion reaction or neonate hemolytic syndrome (Ki-Ho Ko, 2012). Alloimmunization occurs when foreign antigen evokes immune response. This commonly occurs following blood transfusion or in pregnancy, when red cells that bear antigen absent 
from the individual's own blood enter the circulation (Han KS, 2006).

For patients that require transfusion, it is important to conduct pre-operative testing to optimize transfusion safety and minimize complications. In National Blood Bank, 13,000 antibody screening test is performed annually for the patients requesting for blood transfusion. With the Group screen hold protocol (GSH), the antibody screen test is performed for all the patients with blood requisition form irrespective of cross-match tests (Health M. o., 2009)Procedures where blood usage is less than $30 \% \mathrm{GSH}$ is advised. For other procedures where blood usage is more than $30 \%$, the number of units to be kept ready for surgery can be calculated based on the average number of units transfused. For these reasons, it is essential to know the frequency and distribution of unexpected antibodies.

The purpose of this study was to examine the frequency and type of unexpected antibodies found by antibody screening conducted in our hospital from 2015 to 2017

\section{Materials and Methods}

This is a cross-sectional routine to research retrospective study conducted over three years period (2015-2017) in National Blood Bank, JDWNRH. The data were retrieved from the monthly reporting records at NBB from 2015 to 2017. The study was conducted on the patients sample collected in $3 \mathrm{~mL}$ plain red capped tube upon the receipt of blood requisition forms from IPDs and OPDs. The blood requisition forms were sent based on the urgency of the blood required. Irrespective of the urgency of blood requested, antibody screen tests were performed for all the patients sample except for neonates. All samples were centrifuged at $3500 \mathrm{rpm}$ for 5 minutes using Hettich rotofix 32A centrifuge and serum separated.

The antibody screen and identification was performed using standard tube method with commercially available reagents (Dia cell 1, 2, 3) from Bio Rad diagnostic as per standard operating procedure (SOP). The tube method involve three phase of reaction viz IS, $37^{\circ} \mathrm{C}$ and IAT phase. All reactions in all phases are recorded and interpreted. Briefly, the reagent and the sample mix in the tube were centrifuged at $1500 \mathrm{rpm}$ for 5 minutes, followed by 37C incubation for 30 minutes. After that, the tube was washed with normal saline for three times and anti-human globulin reagent added, centrifuged at $1500 \mathrm{rpm}$ for 5 minutes and the reactions were interpreted.

The positive antibody screen test were further tested for antibody identification. An extended 11cell panel was used for antibody identification (Dia panel 11 Bio Rad diagnostic,)

The data were completed in microsoft excel (Ver.2007) and statistically analyzed. Comparison of categorical data and demographic variables were presented as frequency and percentage (\%) using the graphad prism (Ver 4.0). P value of $<0.5$ were considered as statistically significant.

\section{Results}

A total of 39,655 were screened for unexpected antibodies within three years out of which 12057 patients were screened in 2015, 13497 in 2016 and 14101 in 2017 respectively. A total of 155 $(0.39 \%)$ were screened positive out of which 71 $(0.59 \%)$ were tested in 2015, 32(0.24\%) in 2016 and $52(0.37 \%)$ in 2017 respectively (Table 1$)$.

Table 1: Frequency of unexpected antibodies

\begin{tabular}{|l|c|c|}
\hline Year & No. of patients screened for antibody & No. of patients positive with unexpected antibody \\
\hline 2015 & 12057 & $71(0.59 \%)$ \\
\hline 2016 & 13497 & $32(0.24 \%)$ \\
\hline 2017 & 14101 & $52(0.37 \%)$ \\
\hline TOTAL & 39655 & $155(0.39 \%)$ \\
\hline
\end{tabular}

The data showed a total of 14 antibody screen positive for males and 57 for females in 2015, 8 males and 24 females in 2016 and 14 males and 36 females in 2017 respectively. 


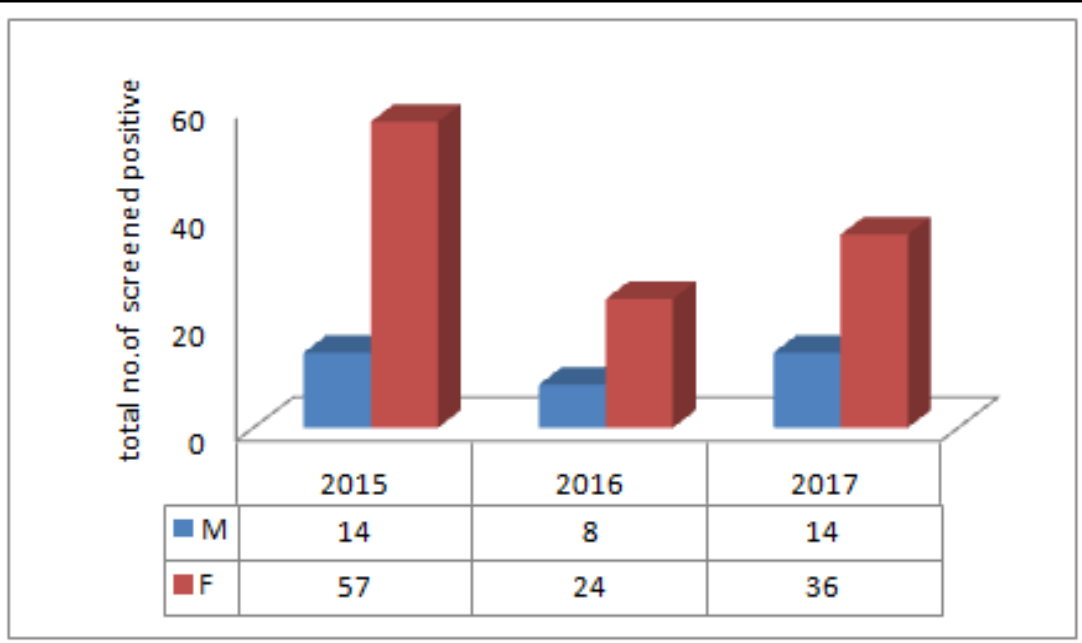

Figure 1 Distribution of unexpected antibodies based on gender

The antibodies commonly identified for three consecutive years were anti-E, anti-Lub and antiLea, (Table 2). Anti-lea was the most common antibody encountered with overall prevalence of
$56.05 \%$. Antibodies belonging to $\mathrm{Rh}$ system accounted for $11.47 \%$ and remaining $24.2 \%$ were undetected.

\begin{tabular}{|l|c|c|c|c|c|c|c|c|}
\hline $\begin{array}{l}\text { Antibody } \\
\text { Specificity }\end{array}$ & \multicolumn{2}{|c|}{2015} & \multicolumn{2}{c|}{2017} & \multicolumn{2}{c|}{ Overall prevalence } \\
\hline & $\mathrm{N}$ & $\%$ & $\mathrm{~N}$ & $\%$ & $\mathrm{~N}$ & $\%$ & $\mathrm{~N}$ & $\%$ \\
\hline Anti-D & 0 & & 1 & 3.13 & 0 & & 1 & 0.64 \\
\hline Anti-c & 0 & & 0 & & 3 & 5.36 & 3 & 1.91 \\
\hline Anti-E & 6 & 8.45 & 2 & 6.25 & 5 & 8.93 & 13 & 8.28 \\
\hline Anti-e & 1 & 1.41 & 0 & & 0 & & 1 & 0.64 \\
\hline Anti-K & 0 & & 1 & 3.13 & 0 & & 1 & 0.64 \\
\hline Anit-Lea & 34 & 47.89 & 18 & 56.25 & 36 & 64.29 & 88 & 56.05 \\
\hline Anti-Leb & 2 & 2.82 & 0 & & 1 & 1.79 & 3 & 1.91 \\
\hline Anti-N & 2 & 2.82 & 0 & & 0 & & 2 & 1.27 \\
\hline Anti-S & 2 & 2.82 & 0 & & 0 & & 2 & 1.27 \\
\hline Anti-Lub & 2 & 2.82 & 1 & 3.13 & 2 & 3.57 & 3 & 1.91 \\
\hline Anti-Jka & 2 & 2.82 & 0 & & 0 & & 2 & 1.27 \\
\hline Unidentified & 20 & 2.82 & 9 & 28.13 & 9 & 16.07 & 38 & 24.2 \\
\hline TOTAL & 71 & & 32 & & 56 & & 157 & \\
\hline
\end{tabular}

\section{Discussion}

Red cell alloimmunization occurs as a response to unexpected antibodies developed after exposure to red cell antigens that are foreign to the patients $(\mathrm{H}$, 2008). This can occur due to transfusion or pregnancy. Additionally, antibody formation can occur due to an anamnestic response when there is repeated exposure to the same red blood cell antigen. Antibodies are not formed weeks or even months after initial exposure to foreign red blood cell antigens. Depending on the repeated exposure to the antigen, antibodies can rapidly appear within 48-72 hours after transfusion and reach a maximum 7-10 days later (ME, 2002) (Heddle NM, 1995).
According to existing international report, the rate of detection of unexpected antibodies after transfusion in healthy people is approximately 11.6\% (Heddle NM, 1995). As shown in our study, the detection rate of antibodies for three consecutive years showed about $0.4-0.7 \%$. This could be due to our study population which consist only of the patients sample that were send to blood bank for crossmatch and blood group screen test, irrespective of the previous history of blood transfusion and pregnancy.

A higher rate of alloimmunization was observed in females than in males. A similar observation was made by Hoeltge et al (Hoeltge GA, 1995) as they found higher percentage of immunized 
females than males. This could be attributed to the antigenic exposure of females during pregnancy in addition to blood transfusion.

The highest frequency of alloantibody in our study was found as anti-lewis. This antibody can occasionally cause hemolytic complications associated with transfusion and is frequently found in expectant mothers with no great clinical significance (Kim BS, 1990). However, in our study, the determination based on past history of pregnancy or transfusion cannot be ruled since no specific analysis was made. But no reported case of delayed transfusion reaction was also reported. In Bhutan, the current practice for providing compatible blood to patients in cases of alloimmunization is still reliant upon random cross-matching of available units in the inventory. Thus, the knowledge of alloantibodies screening and identification is essential in selecting appropriate blood and blood products for transfusion. It also reduces the delays in provision of blood in case of emergencies and surgeries, with GSH protocol.

Since clinically significant antibodies are frequently detected in our patient population and cross-matching is not fully effective as a procedure of ensuring absence of the antigen to which the patient is immunized (Chaudhary R, 2011-5) this practice is neither safe nor costeffective. Antibody screening and if required identification, combined with phenotyping donors to provide a supply of antigen-negative blood is necessary for safe transfusion.

\section{References}

1. HYUNG JOON KIM , YUN HEE LIM , BYUNG HOON YOO, SEUNG-HOON WOO, KI HYUK HONG, AND JUNG WON KIM, A detection of unexpected blood antibody at the time of transfusion was needed, during the operation -A case report. Korean J Anesthesiol 2013 January 64(1): 6568.

http://dx.doi.org/10.4097/kjae.2013.64.1.65
2. HAN KS, PARK MH, KIM SI. Transfusion medicine. 3rd ed. Seoul, Korea Medical Publisher. 2006, pp 153-287

3. KI-HO KO , BYUNG-HOON YOO , KYEMIN KIM , WOO-YONG LEE , JUN-HEUM YON , KI-HYUK HONG , AND TAE-HEE HAN. Frequency of unexpected antibody and consideration during transfusion, Korean $\mathrm{J}$ Anesthesiol 2012 May 62(5): 412-417 http://dx.doi.org/10.4097/kjae.2012.62.5.412

4. SCHONEWILLE H.Red blood cell alloantibodies after transfusion.Leiden: University Press; 2008

5. BRECHER ME. Technical manual. 14th ed. Bethesda, Maryland: American Association of Blood Banks; 2002. pp. 315-397. (ME, 2002)

6. HEDDLE NM, SOUTAR RL, O'HOSKI PL, SINGER J, MCBRIDE JA, ALI MA, ET AL. A prospective study to determine the frequency and clinical significance of alloimmunization post-transfusion. $\mathrm{Br} \quad \mathrm{J}$ Haematol 1995; 91: 1000-5

7. HOELTGE GA, DOMEN RE, RYBICKI LA, SCHAFFER PA. Multiple red cell transfusions and alloimmunization. Experience with 6996 antibodies detected in a total of 159,262 patients from 1985 to 1993. Arch Pathol Lab Med. 1995;119:42-5.

8. KIM BS, KIM HO, SONG KS, LEE SY. Frequency of irregular antibodies detected by type and screen procedure. Korean J Blood Transfus 1990; 1: 47-50.

9. HAN KS, CHO HI, KIM SI. A study on the hemolytic transfusion reactions due to irregular antibodies. Korean J Hematol 1989; 24: 27- 33.

10. CHAUDHARY R, AGARWAL N. Safety of type and screen method compared to conventional antiglobulin crossmatch procedures for compatibility testing in Indian setting. Asian J Transfus Sci. 